\title{
PROBLEMS OF UNKNOWN SIGNIFICANCE: COUNSELING IN THE ERA OF NEXT GENERATION SEQUENCING
}

Fahrioğlu U*

*Corresponding Author: Assistant Professor Umut Fahrioğlu, Department of Medical Biology, Faculty of Medicine, Near East University, Near East Boulevard, Nicosia, Cyprus. Tel: +90-392-675-1000, Ext: 3019. Fax: +90-392-675-1090. E-mail: umutfahrioglu@gmail.com or umut.fahrioglu@neu.edu.tr

\section{Dear Editor,}

Next generation sequencing (NGS) has changed the way we approach the diagnosis, prognosis and treatment of genetic disorders. It gave us base pair (bp) precision, multi-gene approach that can be executed in a timely and cost-effective manner. Despite some minor technical issues in NGS, it comes with great advantages. However, the clinical, and especially, genetic counseling profession will need to rise to the challenge to face some of the new issues, dilemmas and problems this new technology is bringing to the table. Some of the counseling guidelines predate the NGS era and will urgently need to be brought up to par with the technology.

Keywords: Cancer; Challenges; Genetic counseling; Next generation sequencing (NGS); New guidelines.

Conditions such as cystic fibrosis are caused by a single gene, therefore, counseling and testing for this condition is relatively straight forward with well established guidelines to guide the genetic counselor and other health professionals [1]. However, many genetic disorders can be heterogenous in both their genetic and clinical presentation, as demonstrated very clearly with neurological conditions such as glutaric aciduria type I (GA1), Canavan Disease, cancer and neuromuscular disorders [2-8]. Next generation sequencing (NGS) has been changing the way we approach the diagnosis, prognosis and treatment of these complex genetic disorders. It provided us with the ability to investigate the genomes and variations with the precision of base pair (bp) resolution, decreasing cost and making the whole process more effective and informative $[2,9]$.

\footnotetext{
"Department of Medical Biology, Faculty of Medicine, Near East University, Nicosia, Cyprus
}

In today's clinical environment, a timely and cost-effective diagnostic approach to genetic disease would surely include NGS, on top of a gold standard clinical assessment. We are now able to sequence multiple genes at the same time instead of a sequential testing approach traditionally recommended, thus saving precious time and money. Additionally, the new testing approaches are aiming to reduce the uncertainty associated with sequential testing. Despite the advantages of NGS approaches, such as whole exome sequencing (WES) and whole genome sequencing (WGS), they both still do have their technical shortcomings, such as triplet repeat resolution, exome capture, higher falsepositive rates compared to the Sanger method and higher incidence of variants with unknown significance [2,7-14]. The sequencing results have reinforced some of the pathological findings that are already in the common molecular knowledge but some of the genetic consequence contributing to neurological disease might still be able to elude even the best of genome sequencing [9].

With advances in the laboratory coming in leaps and bounds, the clinical and counseling part will also need to keep up. Burden is starting to fall more commonly on the interpretation of the NGS results, requiring a multidisciplinary team, which must include a well-trained genetic counselor. This need becomes more pronounced if the results are ambiguous [2,14]. We are already seeing some issues with NGS being raised for genetic counseling in cancer genetics, nephropathies and arrhythmias. Genetic counselors have always been in the forefront in adopting and integrating new technology into their practice. The new technology would mean that genetic counselors need to cover increasingly more clinically relevant information in their session. The genes that will be tested in the panel, or what it means to analyze a whole genome or exome sequence, the turnaround time, variants of unknown significance and the quality of the test results are just some of 
the difficult topics that need to be covered [2,8,15-17]. This would hold true not just for counseling in cancer genetics but for many specialized areas of counseling including pharmacogenomics population screening, presymptomatic testing and research [18]. The rules and guidelines and regulations for genetic counseling have been established for a long time, and with the technology pushing the laboratory very far, very fast, counseling guidelines and guidance will need to catch up. The latest guidelines and recommendations regarding the impact and use of NGS in areas such as cancer susceptibility could be found on various human genetics society websites. However, the most recent of these documents date back to 2014 $[19,20]$. There is very limited literature on this issue but genetic counseling in the era of NGS is an urgent topic to be addressed, especially in fields such as cancer biology, pediatric disorders such as neuromuscular disorders and multifactorial disease. Many of these fields have guidelines that deal with counseling and informed consent in single gene or sequential gene testing situations. The current guidelines are not designed to deal with multiplex testing situations, where multiple genes are tested simultaneously, and therefore compromise both the counseling and the informed consent process $[8,17]$. According to some of the recommendations, the reason for the lack of practice guidelines is the absence of enough data on the topic [8]. As evidenced by the term "genomic tsunami" the challenge for this type of counseling would be the vastness of the task, not the information that needs to be covered [18].

One of the biggest challenges that accompany the NGS technology is the greater risk of discovering variants of unknown clinical significance [17]. The large number of genes being tested may lead to a number of unwanted findings, such as risk factors for other diseases, or to unclassified variants [18]. Very specialized experts such as molecular pathologists and clinical geneticists are required to determine the pathogenicity of the variants identified and tease out the pathogenic ones from the benign ones [9-11]. Some great questions have already been asked regarding the clinical and patient follow-up implications of NGS and genetically overlapping disease [9]. As the term coined by Ackerman [21] so bluntly puts it, "genetic purgatory" is something to be aware of when we face uncertain results or discover a "variant of unknown significance (VUS)". The uncertainty and the ambiguous results are very difficult for families to deal with. These families and individuals are already dealing with a difficult psychology related to their difficult situation. We add onto it the stress of a genetic test and ambiguous results. The European Society of Human Genetics has put together a comprehensive "guide" for patients regarding NGS [22]. However, even with this information, multiplex testing and the VUS create a situation that is challenging for counselors and other medical professions, let alone patients with limited understanding of genetics [14].

It is of utmost importance for everyone to clearly spell out the benefits and limitations of a testing procedure. Many steps, such as functional assays, will need to be undertaken to discover the molecular implications of the VUS, but at the end of the day, the clinical implications of these findings will remain unclear for the patient in front of us $[11,17]$. Moreover, such approaches take a lot of time to reach a result and the patients and families just do not have the time to wait as they are desperate for a diagnosis or reproductive decisions and there is an urgency attached to all these decisions.

As mentioned earlier, a great effort is already underway to revise counseling guidelines, especially in the field of cancer susceptibility. The lessons and observations from this field would be valuable in setting up new genetic counseling practice guidelines in various fields that are using NGS. The current guidelines are very good at providing the process a great structure. Phenotype-genotype relationships of the one gene being tested is an easy task. However, the task becomes immensely harder when tens, hundreds and sometimes thousands of genes are tested at the same time. Without solid data to guide us it is not possible to tease out exactly what the new guidelines should be. However, these tests are being offered at the moment without some of the comforts of conventional testing procedures. Clear and structured research is required to understand the specific needs of the patients, the counselor and the process itself with the NGS testing on the table. Only then can we try to begin to shape the guidelines. The new guidelines should address the new issues that come hand in hand with NGS such as the vast amount of information produced, some of which could be unsolicited, and the strain this information would put on the pre- and post-test counseling, informed consent, the counselor, and of course, the patient. Some of these issues and challenges have been summarized in Table 1 .

Declaration of Interest. The authors report no conflicts of interest. The authors alone are responsible for the content and writing of this article. 
Table 1. Summary of current guidelines, next generation sequencing challenges and issues to be addressed in future guidelines.

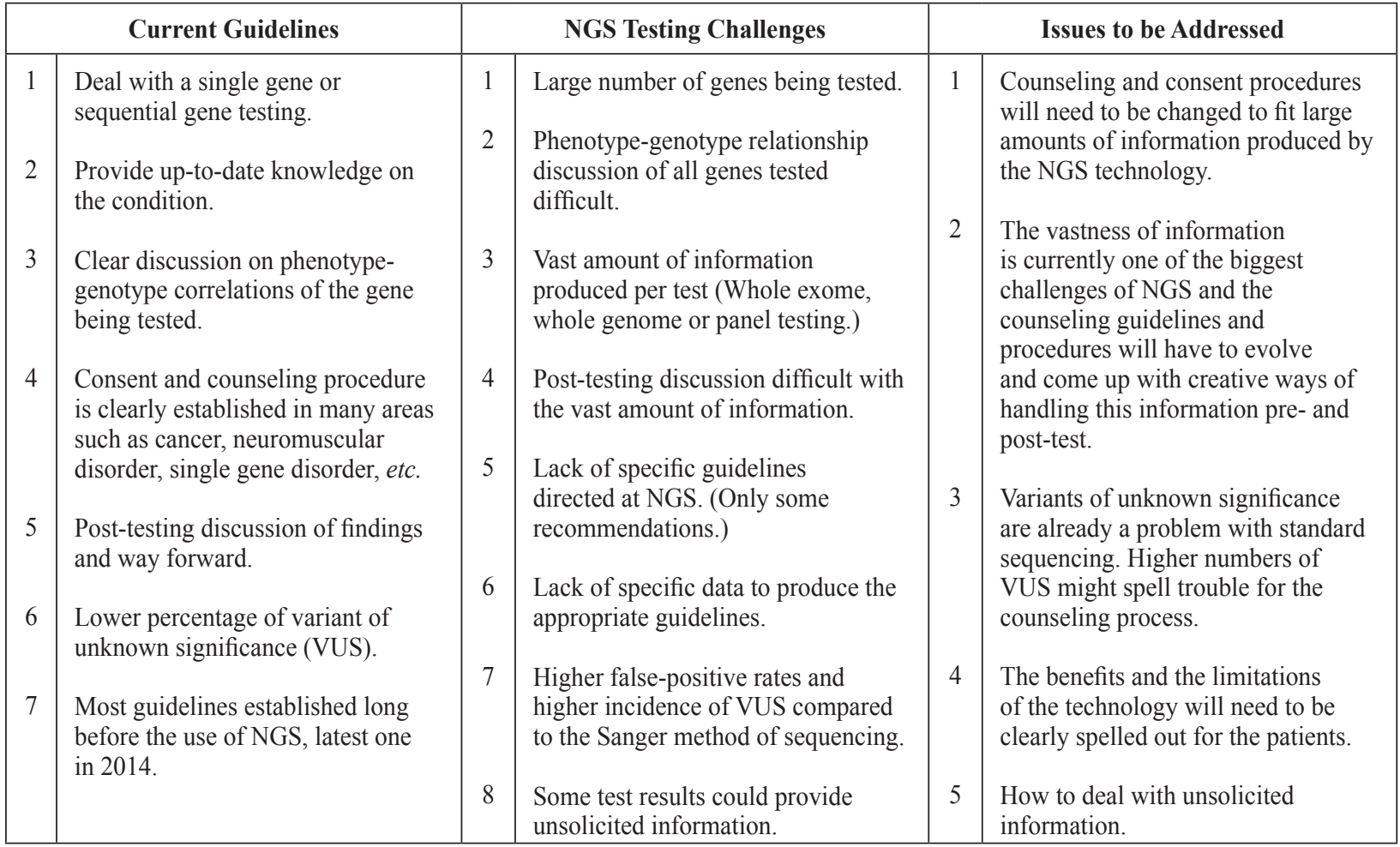

NGS: new generation sequencing; VUS: variant of unknown significance.

\section{REFERENCES}

1. Langfelder-Schwind E, Karczeski B, Strecker MN, Redman J, Sugarman EA, Zaleski C,et al. Molecular testing for cystic fibrosis carrier status practice guidelines: Recommendations of the National Society of Genetic Counselors. J Genet Couns. 2014; 23(1): 5-15.

2. Bergmann C. Advances in renal genetic diagnosis. Cell Tissue Res. 2017; 369(1): 93-104.

3. Keyser B, Mühlhausen C, Dickmanns A, Christensen E, Muschol N, Ullrich K, et al. Disease-causing missense mutations affect enzymatic activity, stability and oligomerization of glutaryl-CoA dehydrogenase (GCDH). Hum Mol Genet. 2008; 17(24): 3854-3863.

4. Kölker S, Christensen E, Leonard JV, Greenberg CR, Boneh A, Burlina AB, et al. Diagnosis and management of glutaric aciduria type I - Revised recommendations. J Inherit Metab Dis. 2011; 34(3): 677-694.

5. Matalon R, Michals K, Kaul R, Mafee M. Spongy degeneration of the brain, canavan disease. Int Pediatr. 1990; 5(2): 121-124.
6. Schober H, Luetschg J, Hoeliner I, Kalb S, Simma B. Canavan disease: A novel mutation. Pediatr Neurol. 2011; 45(4): 256-258.

7. Vasli N, Laporte J. Impacts of massively parallel sequencing for genetic diagnosis of neuromuscular disorders. Acta Neuropathol. 2013; 125(2): 173-185.

8. Fecteau H, Vogel KJ, Hanson K, Morrill-Cornelius $\mathrm{S}$. The evolution of cancer risk assessment in the era of next generation sequencing. J Genet Couns. 2014; 23(4): 633-639.

9. Guerreiro R, Bras J, Hardy J, Singleton A. Next generation sequencing techniques in neurological diseases: Redefining clinical and molecular associations. Hum Mol Genet. 2014; 23(R1): R47-R53.

10. Teoh HL, Sampaio H, Roscioli T, Farrar M. Approaches to genetic diagnosis in neuromuscular conditions in the era of next generation sequencing. J Neurol Neurosurg Psychiatry. 2016; 87(12): 13841385.

11. Acsadi G. Pediatric neurology in the era of genomics. Pediatr Clin North Am. 2015; 62(3): xvii-xviii. 
12. Jiang T, Tan M-S, Tan L, Yu J-T. Application of nextgeneration sequencing technologies in neurology. Ann Transl Med. 2014; 2(12): 125-134.

13. Cheng HH, Klemfuss N, Montgomery B, Higano CS, Schweizer MT, Mostaghel EA, et al. A pilot study of clinical targeted next generation sequencing for prostate cancer: Consequences for treatment and genetic counseling. Prostate. 2016; 76(14): 1303-1311.

14. Rhodes A, Rosman L, Cahill J, Ingles J, Murray B, Tichnell C, et al. Minding the genes: A multidisciplinary approach towards genetic assessment of cardiovascular disease. J Genet Couns. 2017; 26(2): 224-231.

15. Hooker GW, Clemens KR, Quillin J, Vogel Postula KJ, Summerour P, Nagy R, et al. Cancer genetic counseling and testing in an era of rapid change. J Genet Couns. 2017; 26(6): 1244-1253.

16. Mizusawa Y. Recent advances in genetic testing and counseling for inherited arrhythmias. J Arrhythm. 2016; 32(5): 389-397.

17. Domchek SM, Bradbury A, Garber JE, Offit K, Robson ME. Multiplex genetic testing for cancer susceptibility: Out on the high wire without a net? J Clin Oncol. 2013; 31(10): 1267-1270.
18. van El CG, Cornel MC, Borry P, Hastings RJ, Fellmann F, Hodgson SV, et al. Whole-genome sequencing in health care. Recommendations of the European Society of Human Genetics. Eur J Hum Genet. 2013; 21(Suppl 1): S1-S5. http://www.ncbi.nlm.nih.gov/ pubmed/ 23819146. Accessed December 14, 2017.

19. European Society of Human Genetics: Documents \& amp; Links. https://www.eshg.org/documents.0.html. Accessed December 142017.

20. National Society of Genetic Counselors: NSGC Home Page. https://www.nsgc.org/. Accessed December 14 2017.

21. Ackerman MJ. Genetic purgatory and the cardiac channelopathies: Exposing the variants of uncertain/ unknown significance issue. Hear Rhythm. 2015; 12(11): 2325-2331.

22. ESHG sequencing patient information. 2014. https:// www.eshg.org/fileadmin/eshg/documents/ESHG_Patient_leaflet_on_NGS.pdf. Accessed December 14 2017. 